\title{
DAS PRINCIPAIS FORMAS DE SE EFETIVAR A INTEGRAÇÃO DOS PORTADORES DE NECESSIDADES ESPECIAIS NO MERCADO DE TRABALHO
}

\author{
Lourival José de Oliveira ${ }^{1}$ \\ Adriany Cristina Valério
}

\begin{abstract}
RESUMO
O presente artigo aponta algumas das dificuldades enfrentadas pelos portadores de necessidades especiais, principalmente no que concerne a integração social e no mercado de trabalho. Nesse contexto, verificou-se que apesar da legislação existente, os portadores de necessidades especiais não têm seus direito efetivados, o que afronta princípios fundamentais, tais como a dignidade da pessoa humana e direito ao trabalho. Assim, considerando a importância de se inserir os portadores de necessidades especiais na sociedade e no mercado de trabalho, apresenta-se mecanismos de integração e inserção dessas pessoas, analisando instrumentos legais e sociais, tais como habilitação e reabilitação funcional, políticas públicas, além de ações do Ministério Público e da sociedade.
\end{abstract}

Palavras-Chave: portadores de necessidades especiais, integração, legislação protetiva, mercado de trabalho; dignidade do trabalhador.

\begin{abstract}
The present article points some difficulties suffered by people with special needs, mainly to be integrated in the society and in the labor market. In this context, it was verified that, although the existing legislation, people with special needs doesn't have their rights accomplished, which affronts principles as human dignity end the right to work. Finally, considering the importance of engaging people with special needs in the society and in the labour market, the study presents some mechanisms to integrate and include these people, analysing legal and social instruments, such as qualification and functional rehabilitation, public policies and actions of the public prosecutor and the society.
\end{abstract}

Key-words: people with special needs, integration, protective legislation, labour market; dignity of the worker.

\footnotetext{
1 Doutorado em Direito pela Pontifícia Universidade Católica de São Paulo, Brasil(1999)professor associado da Universidade Estadual de Londrina , Brasil, Membro de Comissões de Banca de Concurso Público para admissão de docentes em instituições públicas de ensino superior no Estado do Paraná. Lider de grupos de pesquisa. Advogado
} 


\section{INTRODUÇÃO}

O presente artigo demonstra a discriminação sofrida pelos portadores de necessidades especiais, principalmente nas relações de trabalho, buscando contextualizar o cotidiano dessas pessoas e demonstrar os obstáculos existentes tanto na sua formação pessoal, quanto na sua formação profissional.

Verifica-se, na atualidade, a existência de mecanismos para a integração do portador de necessidade especial na sociedade, tais como a habilitação e reabilitação profissional, a educação especial e legislações que estabelecem desde adaptações arquitetônicas a reserva de mercado.

No entanto, constata-se que apesar dos mecanismos ora citados são inúmeras as dificuldades para integração dos portadores de necessidades especiais, o que se deve à falta de divulgação da legislação protetiva e dos meios de se buscar a sua plena efetivação.

Assim, o artigo em apreço, ressalta a importância de mecanismos coibitivos e preventivos da discriminação como formas de proteger os portadores de necessidades especiais e de exigir a concretização de seus direitos, apontando instrumentos legais, tais quais a ação civil pública, o mandado de segurança coletivo, o mandado de injunção e a ação direta de inconstitucionalidade por omissão.

\section{OS PORTADORES DE NECESSIDADES ESPECIAIS E A PROTEÇÃO CONSTITUCIONAL}

Segundo consenso internacionalmente existente, quando, em consequência de algum mal, o ser humano é vítima de um certo impedimento de ordem física ou mental há a instalação de uma deficiência. Essa deficiência poderá levar ou não a uma incapacidade, ou seja, a uma situação de desvantagem, de inferioridade ${ }^{2}$.

\footnotetext{
${ }^{2}$ MARQUES DA SILVA, Otto. A Epopéia Ignorada. São Paulo: CEDAS, 1986, p. 390.
} 
Neste contexto, salienta-se que o problema dos portadores de necessidades especiais atinge um contingente de $10 \%$ da população brasileira, conforme dados do site do Instituto Brasileiro de Geografia e Estatística - Censo 2000.

$\mathrm{O}$ direito à igualdade auxilia na efetividade dos direitos das pessoas portadoras de deficiência e está assegurado no artigo (art.) $7^{\circ}$, inciso XXXI da Constituição Federal (CF). É notório que o artigo $7^{\circ}$ veio explicitar que a regra da igualdade deve se estender à relação de trabalho, proibindo qualquer forma de discriminação.

$\mathrm{O}$ direito ao trabalho do PNE (portador de necessidade especial) compreende o direito à própria subsistência, forma de afirmação pessoal e social do exercício da dignidade humana. Frisa-se que a dignidade humana é um dos fundamentos da República Federativa do Brasil, prevista no artigo $1^{\circ}$, inciso III da Constituição Federal.

Nas palavras de José Afonso da Silva, a dignidade da pessoa humana é um valor supremo que atrai o conteúdo de todos os direitos fundamentais do homem, desde o direito à vida $^{3}$. Já Adalcy Rachid Coutinho, afirma que o emprego digno é uma das melhores formas de se reduzir a discriminação e a exclusão social ${ }^{4}$.

Para que o portador de necessidade especial possa exercer seu direito ao trabalho é necessário que haja integração social e, para isto, é preciso que o Estado propicie inúmeros direitos a estes cidadãos. Cita-se: direito ao transporte, direito à saúde, direito ao lazer e direito à eliminação das barreiras arquitetônicas.

Diante da realidade social, é visível que os portadores de necessidades especiais não estão habilitados para toda e qualquer profissão. A regra constitucional afirma que "não pode haver qualquer discriminação desde que não haja correlação lógica entre a situação discriminada e o bem protegido 5 ". Por exemplo: não há como se permitir que um cego pretenda a função de motorista. Neste sentido, tem-se que o importante é verificar a

\footnotetext{
${ }^{3}$ SILVA, José Afonso da. Curso de Direito Constitucional Positivo. 28 ed. São Paulo: Malheiros, 2007, p.105.

${ }_{4}$ COUTINHO, Adalcy Rachid. A autonomia privada: em busca da defesa dos direito fundamentais dos trabalhadores. In: Sarlet Ingo Wolfgang (organizador). Constituição, Direitos Fundamentais e Direito Privado. 2 ed. Porto Alegre: Livraria do Advogado, 2006, p.171.

5 ARAUJO, Luiz Alberto David. A Proteção Constitucional das Pessoas Portadoras de Deficiência. $3^{\mathrm{a}}$ ed. Brasília: CORDE, 2003.
} 
habilidade do candidato ao emprego, sem que se faça juízo preconceituoso, o que seria um desrespeito à regra isonômica.

Ressalta-se, ainda, o art. 37, inciso VIII da Lei Maior, no qual o constituinte reservou parte das vagas existentes em cargos e serviços públicos para as pessoas portadoras de deficiência.

Não obstante, as regras constitucionais de seguridade social também abrangem os portadores de necessidades especiais. O art. 196 da CF trata a saúde como direito de todos e dever do Estado. Dessa forma, é dever do Estado fornecer aos PNES (portadores de necessidades especiais) tratamentos, reabilitação, habilitação, dentre outros.

$\mathrm{O}$ direito à educação, tal qual o direito à saúde, é assegurado como sendo um direito de todos e um dever do Estado. No artigo 205 da CF, lê-se que é dever do Estado e da família prestar a educação. Portanto, o dever do Estado de prestar educação também engloba a educação dos portadores de necessidades especiais (PNES).

O capítulo VII da Carta Magna preocupou-se em dar proteção às crianças e adolescentes portadores de deficiência. O inciso II do $\S 1^{\circ}$ e o $\S 2^{\circ}$ do artigo 227 , estabeleceram a criação de programas de prevenção e atendimento especializado aos portadores de deficiência física, sensorial ou mental. Garantiram, também, a integração social do adolescente portador de deficiência mediante o treinamento para o trabalho e convivência.

$\mathrm{Na}$ verdade, o que o dispositivo constitucional revela é a necessidade de adaptação de logradouros e edifícios públicos, com eliminação de barreiras que impeçam ou dificultem o acesso das pessoas portadoras de deficiência. Além disso, prioriza a integração social com o treinamento para o trabalho e a facilitação de bens e serviços coletivos, como o transporte.

Através das Disposições Constitucionais Transitórias, o legislador fez constar que não são somente os logradouros e edifícios públicos a serem construídos que necessitam de adaptações para facilitar o acesso dos PNES, mas também os já existentes.

Verifica-se, em diversos dispositivos, que há direitos consagrados no texto constitucional, os quais só se efetivarão mediante uma legislação integrativa. São medidas que dependem de legislação ordinária. Por outro lado, há um grupo de providências, consagradas em nível constitucional, que exigirão manifestações concretas dos Municípios, 
Distrito Federal, Estados Membros, Territórios e União Federal; “providências estas não mais de ordem normativa, mas de ordem executiva ${ }^{6} "$.

\subsection{LEGISLAÇÃo INFRACONSTITUCIONAL PROTETIVA NO BRASIL}

Dentre as principais legislações protetivas aos portadores de necessidades especiais, destaca-se o Decreto $n^{\circ} 93.481$ de 29 de outubro de 1986, o qual tratou da atuação da administração federal no que concerne às pessoas portadoras de deficiências, instituindo a Coordenadoria para Integração da Pessoa Portadora de Deficiência (CORDE).

O apoio e integração social dos deficientes, a instituição da tutela jurisdicional de interesses coletivos ou difusos destas pessoas e a atuação do Ministério Público (MP), foram estipulados pela Lei $\mathrm{n}^{\mathrm{o}} 7.853$ de 24 de outubro de 1989. Esta mesma lei foi regulamentada pelo Decreto n 3.298 de 20 de dezembro de 1999, dispondo sobre a Política Nacional para a integração da Pessoa Portadora de Deficiência e consolidando normas de proteção.

Na Lei que dispõe sobre os Planos de Benefícios da Previdência Social, Lei no 8.213 de 24 de julho de 1991, foi introduzida a chamada "reserva de mercado", a qual obriga empregadores a reservar certo número de vagas em percentuais aos beneficiários reabilitados ou pessoas portadoras de deficiência. Explicitando, a empresa com 100 (cem) ou mais empregados está obrigada a preencher de $2 \%$ a $5 \%$ dos seus cargos com beneficiários reabilitados ou pessoas portadoras de deficiências em proporções que variam de acordo com o número de empregados.

“Caso a empresa já tenha seu quadro de vagas preenchido, sem atender ao percentual de vagas, deve fazê-lo gradativamente, conforme Ordem de Serviço Conjunta do INSS n ${ }^{\circ}$ 90/1998 7 ", a qual estabelece a sistemática de fiscalização, avaliação e controle de vagas destinadas ao beneficiário reabilitado e à pessoa portadora de deficiência.

\footnotetext{
${ }^{6}$ ARAUJO, op. cit., p. 96 e 97.

${ }^{7}$ BARROS, Alice Monteiro de. Curso de Direito do Trabalho. 2 ed. São Paulo: LTr, 2006, p. 1.140 .
} 
A Lei que dispõe sobre a organização da Assistência Social (Lei nº 8.742/1993), garantiu em seu art. $2^{\circ}$, inciso $\mathrm{V}$, a concessão de um salário mínimo de benefício mensal às pessoas portadoras de deficiência que comprovem não possuir meios de prover a própria manutenção ou de tê-la provida por sua família.

Destaca-se, ainda, o contrato de aprendizagem, que a par da inovação trazida pela Medida Provisória $n^{\circ}$ 251/2005 (convertida na Lei $n^{\circ} 11.180 / 2005$ ) em relação à idade máxima do aprendiz, previu a possibilidade de celebração de contrato de aprendizagem com deficientes. Nestas hipóteses, a idade máxima prevista no caput do art. 428 não se aplica aos aprendizes com deficiência. Outrossim, quanto aos aprendizes com deficiência mental, a comprovação da escolaridade deve considerar, sobretudo, as habilidades e competências relacionadas com a profissionalização.

\subsection{Atribuições da União, dos Estados E dos MunicíPIOS}

Diversos dispositivos consagrados no texto constitucional só se efetivarão mediante uma legislação integrativa, ou seja, necessitam de leis complementares para a completa produção de seus efeitos. Por outro lado, há um grupo de providências consagradas em nível constitucional, que exigirão manifestações concretas da União, dos Estados e dos Municípios ${ }^{8}$.

A Constituição de 1988, em seu artigo 22, arrola as competências legislativas da alçada da União, assuntos que competem à União legislar privativamente. Contudo, o parágrafo único deste mesmo artigo diz que lei complementar poderá autorizar os Estados a legislarem sobre questões específicas das matérias relacionadas no artigo supracitado ${ }^{9}$.

No art. 23 da Carta Magna há a competência concorrente, a qual pode ser cumprida tanto pela União, como pelos Estados, pelo Distrito Federal e os Municípios. Já no artigo 24, do mesmo diploma, há regras específicas para a legislação sub-constitucional, a qual

\footnotetext{
${ }^{8}$ ARAUJO, op. cit., p. 95.

${ }^{9}$ BASTOS, Celso Ribeiro. Curso de Direito Constitucional. 19a ed. São Paulo: Saraiva, 1998, p.297.
} 
abrange matérias que a União pode legislar de forma concorrente, com a exclusão dos Municípios.

Dessa forma, é possível afirmar que compete à União a elaboração de normas gerais e aos Estados a elaborações de norma que atenda às peculiaridades do tema. Caso haja omissão legislativa federal, o Estado poderá legislar plenamente e surgindo lei federal, há suspensão da eficácia das normas estaduais de caráter geral.

Assim, por ser competência comum, há uma solidariedade passiva na responsabilidade dos Municípios, Estados, Distrito Federal e União ${ }^{10}$. Deve-se, ainda, atentar-se ao fato de não se tratar de competência legislativa, mas sim de imposição de ônus consistente na prestação de serviços e atividades.

Quanto aos Municípios, compete dispor sobre tudo aquilo que diga respeito ao seu interesse local. O inciso II do artigo 30 da Constituição Federal, expressa que compete ao Município suplementar a legislação federal e a estadual no que couber. Assim, "mesmo em assuntos sobre os quais nenhuma competência possuía o Município, pode ele agora suprir omissões da legislação federal e estadual, sem, contudo, violentá-la ${ }^{11}$ ".

O contexto atual demonstra que a legislação que visa a proteção dos PNES é muito geral quando abrange a competência da União e muito específica quando se reporta aos Municípios. Assim, os Estados devem legislar de forma com que os Municípios especifiquem as leis por estes elaboradas, visando o bem estar social e a aplicação do princípio constitucional da igualdade. Todos (União, Estados e Municípios) devem trabalhar em conjunto em busca da efetividade da legislação elaborada.

Dessa forma, verifica-se que a proteção dos PNES não é apenas constitucional, sendo necessárias leis específicas para situações peculiares. Contudo, apesar da existência de inúmeras leis de proteção aos portadores de necessidades especiais, um grande problema persiste, a eficácia destas leis, seja pela discriminação, seja pela dificuldade de aplicação.

\section{DA NÃO DISCRIMINAÇÃO AOS PORTADORES DE NECESSIDADES ESPECIAIS}

\footnotetext{
${ }^{10}$ ARAUJO, op. cit., p. 99.

${ }^{11}$ BASTOS, op. cit., p.312.
} 
Os Estados devem adotar um papel mais ativo, através de ações afirmativas, que consistem em um amplo e planejado processo de transformação da sociedade e do próprio Estado, com o fim de assegurar uma efetiva igualdade entre raças e gêneros no mercado de trabalho e identificar e eliminar todas as práticas discriminatórias.

Há duas formas de se discriminar, uma consiste em outorgar benefício legítimo a pessoas ou grupos, discriminando-os favoravelmente em detrimento de outras pessoas em iguais condições; outra é impor obrigação, ônus, dever, sanção ou qualquer outro sacrifício a pessoas, discriminando-as em face dos outros na mesma situação ${ }^{12}$. Esta última discriminação é inconstitucional.

Infere-se deste contexto que a discriminação no mercado de trabalho atinge um grande contingente populacional, o que acarreta em prejuízos econômicos e sociais para a sociedade, impedindo que muitos PNES trabalhem em busca de melhores condições de vida.

O mercado de trabalho é competitivo e segregativo, excluindo os menos aptos. Geralmente, dentro desse contingente de excluídos encontram-se os portadores de necessidades especiais. Nesse diapasão, destaca-se que as barreiras para a inserção dos PNES no mercado de trabalho são grandes e as oportunidades são pequenas, assim, este grupo de pessoas é "injustamente afastado da vida comum - maneira deficiente de tratar pessoas eficientes ${ }^{13}$,"

As limitações dos PNES são variadas e não podem ser tratadas de maneira genérica. O fato é que grande parte dos PNES apresentam limitações superáveis mediantes pequenas acomodações no local de trabalho, na arquitetura e nos meios de transporte. Contudo, devido à persistência de desinformação e inadequação do ambiente físico e social, os PNES continuam sem condições de competir no mercado de trabalho ${ }^{14}$.

Dentre os PNES que podem trabalhar, é ainda comum a rejeição de profissionais qualificados pelo simples fato de serem portadores de alguma limitação, mesmo que esta

\footnotetext{
${ }^{12}$ SILVA, José Afonso da. Curso de Direito Constitucional Positivo. 28 ed. São Paulo: Malheiros, 2007, p. 226 e 228.

${ }^{13}$ PASTORE, José. Oportunidades de Trabalho para Portadores de Deficiência. São Paulo: LTr, 2000, p.14.

${ }^{14}$ Ibidem, p. 70.
} 
não afete o desempenho no trabalho ${ }^{15}$. É a desconsideração da eficiência e o enaltecimento da deficiência.

As grandes empresas geralmente justificam a ausência ou o baixo número de empregados portadores de deficiência na falta de qualificação. Já as pequenas e médias empresas alegam que a obrigatoriedade legal as força a assumir despesas arquitetônicas e de equipamentos que não têm condições de $\operatorname{arcar}^{16}$.

A educação, por si só, não é garantia de emprego. Contudo, ajuda as pessoas a se empregarem, a manterem e a mudarem de emprego, o que é essencial quando se reporta à realidade dos PNES.

A integração do PNE no mercado de trabalho é uma tarefa árdua, visto que os empresários, devido ao preconceito, preocupados com o volume de produção/ serviço, dificilmente empregam os portadores de necessidades especiais ${ }^{17}$.

A fraca participação dos PNES no mercado de trabalho também decorre da carência de ações, estímulos e instituições que viabilizem, de forma concreta, a formação, habilitação, reabilitação e inserção dos portadores de deficiência no mercado de trabalho ${ }^{18}$. Assim, é crucial a conscientização pela não discriminação.

\section{DAS FORMAS DE PROTEÇÃO AOS PORTADORES DE NECESSIDADES ESPECIAIS}

\subsection{DA PROTEÇÃo ATRAVÉS DA EMPRESA}

Hoje, a sociedade tem preocupações ecológicas, de segurança, de proteção e defesa do consumidor e de defesa de grupos minoritários, sendo que estes fatores, aliados à estratégia econômica das empresas, exercem uma grande impulsão nos investimentos de procedimentos administrativos e operacionais que auxiliem a inclusão de grupos minoritários no mercado de trabalho.

\footnotetext{
${ }^{15}$ Ibidem, p. 25.

${ }^{16}$ Pastore, op. cit., p. 106.

${ }^{17}$ RIBAS, João Baptista Cintra. O que são Pessoas Deficientes. São Paulo: Brasiliense, 1985, p. 85.

${ }^{18}$ PASTORE, op. cit., p.59.
} 
Por fim, "o equilíbrio de uma sociedade depende da integração de grandes fatores: governo, família e empresa ${ }^{19}$ ". Tendo em vista que a família luta para defender sua posição frente aos grandes avanços da sociedade e que o governo é moroso devido às estruturas burocráticas, a empresa torna-se uns dos meios mais efetivos e viáveis de se diminuir as desigualdades, sejam estas sociais ou econômicas.

A mudança na concepção dos paradigmas da ação social demonstra que há um esforço da empresa em interagir com a coletividade. A idéia de ação positiva não abarca somente as iniciativas de ordem empresarial, mas, em sua maioria, a força de um movimento que se abre para o modo como a empresa encara sua relação com o ambiente social ${ }^{20}$.

A empresa é um importante agente social, dotado de relevante poder sócioeconômico. É responsável pela geração de empregos, pelo recolhimento de tributos e movimenta a economia com a compra e venda de bens e prestação de serviço. Toda empresa deve cumprir uma função social, pois "na medida em que a propriedade deve atender à função social, e não tendo havido distinção entre qualquer espécie de propriedade, por certo se inclui a propriedade empresária ${ }^{21}$ ".

Dessa forma, a função social da empresa é alcançada quando, além de realizar os papéis elencados no parágrafo anterior, ela observa outros valores, cuja maioria está na Constituição Federal de 1988, como por exemplo, o bem estar social.

A empresa não deve buscar unicamente o lucro, mas também deve voltar-se a interesses socialmente relevantes, buscando um equilíbrio da economia de mercado. Esta responsabilidade da empresa com o meio em que está inserida é uma das maneiras de se efetivar os interesses sociais previstos na Constituição Federal.

Contudo, a adesão da empresa aos princípios da responsabilidade social empresarial não deve ser concretizada com a expectativa de gerar impactos imediatos na imagem da empresa, mas sim, como resultado de uma reflexão madura e de uma decisão que abranja um conjunto de políticas e práticas empresariais.

Os princípios vetores de uma ordem econômica sustentada e equilibrada, em que há respeito ao direito do consumidor, ao meio ambiente e à própria função social da

\footnotetext{
${ }^{19}$ KARKOTLI, Gilson. Responsabilidade Social Empresarial. Petrópolis, RJ: Vozes, 2006, p.124.

${ }^{20}$ KARKOTLI, op. cit., p. 124.

${ }^{21}$ PETTER, Lafayete Josué. Princípios Constitucionais da Ordem Econômica: O significado e o alcance do art. 170 da Constituição Federal. São Paulo: Revista dos Tribunais, 2005, p. 217.
} 
propriedade, quando unidos e interligados, dão sustentação constitucional à função social empresarial $^{22}$.

Independente da liberdade de contratar, ao fazê-lo, a empresa deve cumprir a sua função social, buscando suprir o interesse social e econômico. A empresa pode gerar oportunidades, as quais auxiliariam os PNES a terem os seus direitos efetivados, seja de uma vida digna, seja na diminuição da discriminação.

\subsection{DA PROTEÇÃo AtraVÉS DO MinistéRIo PÚBLICO}

A existência de legislação em prol dos portadores de necessidades especiais, não é suficiente para garantir que os direito a eles atribuídos sejam efetivados. Neste contexto, surge o Ministério (MP) como instituição designada para assegurar os interesses dos PNES, visando garantir a sua cidadania, inclusão social e dignidade.

Atualmente o MP é tido como instituição permanente, essencial à função jurisdicional do Estado, incumbindo-lhe a defesa da ordem jurídica, do regime democrático e dos interesses sociais e individuais indisponíveis, respeitando sempre os princípios da unidade e indivisibilidade.

As leis elaboradas, com destaque à lei $n^{\circ} 7.853 / 1989$, passaram a dar respaldo à atuação Ministerial, possibilitando o início de uma verdadeira revolução para retirar o PNE da condição de marginalizado e excluído, elevando-o à cidadão com dignidade e respeito.

Através da legitimidade conferida ao promotor de justiça para atuar em defesa dos PNES, vários trabalhos na busca da inclusão passaram a ser desenvolvidos. A inclusão abrange aspectos econômicos, sociais, educacionais, ambientais e relacionados à saúde ${ }^{23}$.

O órgão do Ministério Público responsável pelas relações de trabalho é o Ministério Público do Trabalho (MPT), representado pelo promotor de justiça do trabalho. Com relação à inclusão econômica, o promotor de justiça do trabalho deve fiscalizar a reserva de vagas aos PNES, tanto no preenchimento de vagas em empresas, como na realização de concursos

${ }^{22}$ GAGLIANO, Pablo Stolze. Novo Curso de Direito Civil. Volume IV: Contratos. 3 ed. São Paulo: Saraiva, 2007.

${ }^{23}$ FERREIRA, Luiz Antonio Miguel. A Inclusão da Pessoa Portadora de Deficiência e o Ministério Público. Disponível em: <http://www.institutointegrar.org.br/arquivos/A\%20INCLUSO\%20PESSOA\%20PORTADORA\%2 0DE\%20DEFICIENCIA.doc.>. Acesso em: 22 de jan. 2009. 
públicos. Esta forma de inclusão garante ao PNE o encontro de uma vaga no mercado de trabalho, auxiliando no desenvolvimento do setor econômico.

Quanto à inclusão social, o promotor de justiça deve verificar as possibilidades de integração do PNE na sociedade, o que abrange a reserva de vagas em estacionamentos públicos, a disponibilidade de meios de transporte adaptados e a instalação de mecanismos que auxiliem os PNES na concretização de igualdades de condições no contexto social em que vivem.

No que tange a inclusão educacional, o papel do promotor de justiça é garantir que todos tenham acesso à educação e qualificação, não permitindo que ocorra a exclusão de um aluno com necessidades especiais devido ao preconceito e despreparo social.

Há de se mencionar que o ambiente precisa estar preparado para que ocorra a integração dos portadores de necessidades especiais e, para que isto aconteça, é necessário a queda das barreiras arquitetônicas. Apesar da existência de leis que visem a eliminação dessas barreiras, muitos são os ambientes que precisam ser modificados, sendo crucial para que a legislação tenha efetividade, a atuação do Ministério Público do Trabalho.

Em síntese, o trabalho do Promotor de Justiça do Trabalho deve ser realizado no sentido de buscar a efetividade dos direitos fundamentais consignados na Constituição e garantidos pela legislação ordinária, com vista à aplicação do princípio da igualdade como expressão máxima da cidadania e dignidade da pessoa humana ${ }^{24}$.

Deve-se destacar que um dos principais instrumentos de proteção aos PNES é a Ação Civil Pública. Esta modalidade de ação está prevista no art. 129, inciso III da Constituição Federal.

Contudo, esta legitimação ativa do Ministério Público, não impede a de terceiros, nas mesmas hipóteses, conforme $\S 1^{\circ}$ do mencionado artigo 129. Destaca-se a Lei $\mathrm{n}^{\mathbf{o}}$ 7.347/1985, que estabeleceu em seu art. $6^{\circ}$ que qualquer pessoa poderá e o servidor público deverá provocar a iniciativa do MP, ministrando-lhe informações sobre os fatos que constituam objeto da ação civil.

\footnotetext{
${ }^{24}$ FERREIRA, op. cit.
} 
Importante salientar que, além das funções do Ministério Público, anteriormente indicadas, o artigo 129 da CF, o muniu com poderes de investigação, como a requisição de documentos, de informações e de diligências investigatórias ${ }^{25}$.

Assim, conclui-se que o Ministério Público tem função crucial na proteção e efetivação dos direitos dos PNES, incumbindo também à sociedade atuação conjunta ao MPT, o que pode ser feito através de denúncias e fiscalização.

\subsection{DA PROTEÇÃo AtRAVÉS DAS AsSOCIAÇÕES}

Para a tutela dos interesses difusos e coletivos o sistema constitucional elegeu, além do MP, as associações, desde que expressamente autorizadas, conforme o art. $5^{\circ}$, incisos LXIX e LXX, alínea b. Para que uma associação ajuíze mandado de segurança coletivo visando a defesa dos PNES, "além das proteções individuais em apreço, é imprescindível a existência de um liame entre o bem protegido e o interesse dos associados ${ }^{26}$,. O direito à integração social do PNE como um conjunto de ações administrativas e legislativas "é de interesse coletivo e difuso, já que atinge o interesse de um grupo de pessoas ${ }^{27}$.

Deve-se atentar para a alínea "b" do inc. LXX do art. 50, que demonstra a não necessidade de haver direito líquido e certo, mas apenas interesse. Assim, o direito líquido e certo será exigido quando a entidade impetra o mandado de segurança coletivo na defesa de direito subjetivo individual, já quando impetrado na defesa de interesse coletivo de seus membros ou na defesa de interesse coletivo difuso, exige-se, ao menos, a ilegalidade e a lesão do interesse que o fundamenta ${ }^{28}$.

Assim, a busca pela efetivação dos direitos dos PNES através das associações é um importante mecanismo de se atenuar a discriminação e de se concretizar os princípios presentes na Constituição Federal.

Todavia, o principal instrumento colocado à disposição dos PNES é a busca por informação e a conscientização da sociedade. É necessário que os portadores de necessidades especiais e toda a sociedade conheçam as leis que os protegem e exijam a sua

\footnotetext{
${ }^{25}$ ARAUJO, op. cit., p. 374.

${ }^{26}$ ARAUJO, op. cit, p. 111.

${ }^{27}$ ARAUJO, op. cit., p. 109.

${ }^{28}$ SILVA, op. cit., p. 461.
} 
efetividade. É crucial a reivindicação de todos os direitos positivados, sejam eles constitucionais ou não.

\subsection{DA PROTEÇÃO INDIVIDUAL}

$\mathrm{O}$ ataque individual à omissão legislativa ou contra a inércia do administrador é feito através do mandado de injunção e da ação direta de inconstitucionalidade por omissão. $\mathrm{O}$ primeiro encontra-se no art. $5^{\circ}$, inciso LXXI da CF e pode ser ajuizado por qualquer pessoa que se sinta impedida de exercitar um direito constitucionalmente assegurado pela falta de norma regulamentadora. Esta medida destina-se a obter sentença que declare a omissão legislativa, com a finalidade de que se dê ciência ao órgão omisso dessa declaração para que sejam adotadas as providências necessárias ${ }^{29}$.

Deste modo, a principal função do mandado de injunção consiste em conferir imediata aplicabilidade à norma constitucional inerte em virtude da ausência de regulamentação ${ }^{30}$.

Já a ação direta de inconstitucionalidade por omissão não tem por objetivo a defesa de um direito subjetivo, de um interesse juridicamente protegido lesado ou na iminência de sê-lo. É voltada inteiramente para a defesa da Constituição, declarando a mora do legislador frente a uma omissão legislativa e adotando medidas para o suprimento desta omissão constitucional, que será feita por iniciativa do próprio órgão remisso.

Dessa forma, o PNE não depende de terceiros para buscar a efetivação de seus direitos, sendo necessária a divulgação de informações que tragam a se conhecimento a existência desses mecanismos.

\subsection{DA IMPORTÂNCIA DE PolíticAs PÚblicas Protecionistas}

\footnotetext{
${ }^{29}$ BASTOS, op. cit., p. 243.

${ }^{30}$ SILVA, op. cit., p. 448.
} 
Políticas Públicas são um conjunto de ações coletivas voltadas para a garantia dos direitos sociais, configurando um compromisso público reponsável por determinada demanda em diversas áreas.

As políticas públicas colocadas à proteção dos PNES encontram respaldo principalmente na legislação específica. Devido à importância e necessidade de implantação de políticas públicas em prol dos PNES, vários órgãos foram criados, dentre eles cita-se a já mencionada CORDE e o Conselho Nacional dos Direitos da Pessoa Portadora de Deficiência (CONADE).

A CORDE é o órgão de Assessoria da Secretaria Especial dos Direitos Humanos da Presidência da República, responsável pela gestão de políticas voltadas para integração da pessoa portadora de deficiência, tendo como eixo focal a defesa de direitos e a promoção da cidadania. Já o CONADE tem como objetivo acompanhar e avaliar o desenvolvimento da Política Nacional para Integração da Pessoa Portadora de Deficiência e das políticas setoriais de trabalho, educação, saúde, assistência social, transporte, cultura e lazer voltadas a este grupo social.

No setor da saúde, o desenvolvimento de políticas públicas é importante para propagar programas nutricionais que visem suprir as carências alimentares causadoras do grande número de deficiências; executar e disseminar a vacinação de rotina; desenvolver ações de educação em saúde; criar ou ampliar e potencializar Unidades de Reabilitação para o atendimento de diversas deficiências e síndromes, dentre outras medidas que visem o bem estar físico do PNE.

Já nos setores da educação e cultura, as políticas públicas podem auxiliar na adequação das bibliotecas públicas e das escolas às necessidades individuais de seus usuários, no investimento da formação inicial e continuada dos profissionais da educação, na habilitação e qualificação dos PNES e no estabelecimento de convênios entre as entidades que prestam serviços a deficientes e instituições que mantém cursos superiores para que sejam realizados estágios nestas entidades.

Com relação ao transporte, as políticas públicas devem viabilizar a unificação dos critérios de isenção tarifária do transporte coletivo em âmbito Federal, possibilitando a criação da carteira de transporte nacional para as pessoas com deficiência. 
Outras medidas também devem ser adotadas, como incluir ônibus com acessibilidade universal em cada linha, unificar os critérios em âmbito Federal para utilização de vagas de estacionamento demarcadas para pessoas com deficiência e colocar legendas em Braile (itinerário) e piso tátil para pessoas com deficiência visual nos pontos de ônibus e terminais rodoviários e ferroviários.

A concretização de políticas públicas não depende somente de intervenções governamentais, mas, sobretudo, do engajamento de várias instituições, em especial das empresas, todas elas movida por uma combinação de princípios de responsabilidade social e de cálculo econômico ${ }^{31}$.

Já o trabalho protegido é o que ocorre em entidades que se dedicam especificamente ao amparo, à recuperação profissional e ao desenvolvimento pessoal de PNES que nelas trabalham $^{32}$. Atualmente, a forma mais comum de trabalho protegido é em cooperativas sociais, as quais são operadas por Organizações não governamentais (ONGs), com pessoal especializado, que recebem recursos públicos e privados para prover aos PNES as oportunidades que eles normalmente não conseguem no mercado de trabalho. Portanto, o trabalho protegido também é uma espécie de política pública que visa a inserção do PNE em atividades laborativas.

Os PNES apresentam limitações, as quais muitas vezes em nada alteram sua capacidade de realizar inúmeras funções. Contudo, com o desenvolvimento no mercado de trabalho na atualidade, para que se consiga uma vaga é necessário qualificação e adaptação, principalmente quando se trata de PNES, o que pode ser facilitado através da elaboração e efetivação de políticas públicas.

\subsection{HABILITAÇÃO E REABILITAÇÃo FUNCIONAL}

\footnotetext{
${ }^{31}$ PASTORE, op. cit., p. 138.

${ }^{32}$ Ibidem, p. 153.
} 
A Organização Internacional do Trabalho (Convenção $n^{\circ} 159$ de $1^{\circ}$ de junho de 1983) estabelece como finalidade da reabilitação profissional a manutenção e a progressão do PNE no mercado de trabalho, promovendo, consequentemente, a sua inclusão social.

A Lei $n^{\circ} 7.853$ de 24 de outubro de 1989, prevê em seu artigo 1º, inciso I, alínea "c", o direito à criação de uma rede de serviços especializados em reabilitação e habilitação. Além disso, em seu inciso III, alíneas “c” e "d", estipula a promoção de ações eficazes que propiciem a inserção dos PNES no mercado de trabalho e a adoção de legislação específica que estabeleça a reserva de mercado.

Os sistemas de seguridade social assumem um papel importante na reabilitação profissional em todo o mundo. A adaptação é o conjunto de atividades voltadas para quem traz uma limitação desde o nascimento e para aqueles que precisam se qualificar para desempenhar determinadas funções no ambiente de trabalho. Já a reabilitação é a atenção prestada aos PNES, em geral, após um acidente ${ }^{33}$.

A reabilitação é uma atividade cara e complexa, contudo, a manutenção dos PNES afastados e recebendo ajuda da Previdência Social é mais onerosa ao Estado. O incentivo a programas de reabilitação profissional é um investimento a longo prazo e que pode trazer inúmeras vantagens, tais como a redução da discriminação e o aprimoramento do mercado de trabalho.

As ações a serem desenvolvidas nos programas de reabilitação profissional têm como objetivo a construção de um contexto inclusivo de trabalho, envolvendo a implantação de serviços de apoio à pessoa portadora de necessidades especiais e ações dirigidas à sociedade, destinadas a eliminar barreiras sociais e físicas no ambiente e no local de trabalho. Além disso, a atuação junto ao portador de necessidade especial implica na oferta de serviços diretos, voltados à formação profissional, à reabilitação, à capacitação profissional, à educação básica e a serviços de apoio.

Os programas de habilitação e reabilitação profissional devem ter duas frentes de atuação: ações internas em empresas e externas junto à comunidade ${ }^{34}$. Nas ações internas, a capacitação profissional pode ocorrer tanto nas oficinas de trabalho quanto no ambiente real

\footnotetext{
${ }^{33}$ PASTORE, op. cit., p. 94.

${ }^{34}$ BUENO, Carmem Leite. A Reabilitação Profissional e a Inserção da Pessoa com Deficiência no Mercado de Trabalho. <http://www.prt12.mpt.gov.br/prt/guia/textos/reabilita.pdf>. Acesso em: 11 de jan. 2009.
} 
de trabalho. Para que isto ocorra é necessário que o Estado desenvolva ambientes especializados ou realize parcerias com algumas empresas. Com relação às ações externas, é necessário o trabalho junto ao Poder Público para garantir uma legislação adequada de proteção ao trabalhador e uma política de prevenção de deficiências nos planos nacional, federal e municipal.

À empresa que reabilita o empregado, abre-se inclusive a perspectiva de cumprir a quota de portadores de deficiência e reabilitados, de que trata o art. 93, da Lei $n^{\circ}$ 8.213/91. Há, também, a possibilidade de obter economia de até $50 \%$ do valor pago a título de seguro de acidente de trabalho (SAT), incidente sobre a folha de pagamento, nos moldes do art. 10, da Lei $n^{\circ} 10.666 / 2003$.

Para que o processo de habilitação ou reabilitação profissional seja viável e eficaz é plausível que os empregadores necessitem de estímulos para contratar e compensar os custos de admissão, adaptação e retenção dos portadores de necessidades especiais nos seus ambientes de trabalho, o que pode ocorrer de três formas: a complementação salarial, a ajuda para adaptação e a isenção de contribuições ${ }^{35}$.

A complementação dos salários seria um repasse às empresas de uma parcela do salário para compensar as despesas de acomodação ou eventual diferencial de produtividade do PNE. Já a ajuda para adaptação, é uma forma pela qual as empresas e as entidades de portadores de deficiência recebem recursos para cobrir parte dos custos de investimento e adaptação $^{36}$. No que tange à isenção de contribuições, os empregadores podem receber isenção total ou parcial de encargos sociais ao empregarem portadores de necessidades especiais $^{37}$.

A habilitação e a reabilitação profissional são importantes elementos na retirada de PNES da condição de beneficiários ou pensionistas, passando-os para a categoria de trabalhadores ativos no mercado de trabalho.

\footnotetext{
${ }^{35}$ PASTORE, op. cit., p. 149.

${ }^{36}$ Ibidem, p. 150.

${ }^{37}$ Ibidem, p. 150.
} 


\section{PROPOSTAS PARA APERFEIÇOAR A PROTEÇÃO AOS PORTADORES DE NECESSIDADES ESPECIAIS}

As mudanças constantes no mercado de trabalho aliadas à competitividade empresarial, gera a necessidade da utilização de mecanismos cada vez mais avançados, incluindo no campo das comunicações. Nessa perspectiva, o teletrabalho surge como resultado dessas necessidades e como uma das possíveis soluções de engajamento do PNE no mercado formal de trabalho ${ }^{38}$.

O teletrabalho possibilita o trabalho à distância, rompendo com as barreiras geográficas e reduzindo problemas como o da locomoção e da adaptação, o que aumenta as possibilidades do PNE se integrar ao mercado de trabalho.

Outra vantagem do teletrabalho é a flexibilização do local de trabalho, permitindo ao PNE que realize suas funções em seu domicílio, transcendendo limites territoriais, os quais podem ser transregional, transnacional e transcontinental ${ }^{39}$.

Não obstante, muitas empresas não contratam os PNES devido ao custo de adaptação do ambiente de trabalho e o PNE, cuja sua residência já está adaptada às suas necessidades, pode realizar o seu serviço de forma produtiva e confortável sem trazer maiores custos às empresas.

Assim, a utilização do teletrabalho apresenta inúmeras vantagens, como a redução do espaço imobiliário, a diminuição de custos inerentes à aquisição de locais, aluguéis, manutenção e transporte ${ }^{40}$. Além disso, propicia melhor atenção aos clientes, maior produtividade pelo empregado (com a eliminação no tempo perdido no trânsito), além da empresa não sofrer com greves no sistema de transporte, acidentes no trajeto do trabalho e fenômenos metereológicos.

\footnotetext{
${ }^{38}$ DARCANCHY, Mara Vidigal. Teletrabalho e Acesso das Pessoas Portadoras de Necessidades Especiais ao Meio Ambiente do Trabalho. Revista Justiça do Trabalho, Porto Alegre: HS Editora, a. 23, n. 865, Janeiro/2006.

${ }^{39}$ BARROS, op. cit., p. 304.

${ }^{40}$ Ibidem, p. 306.
} 
Além disso, o teletrabalho também pode ser realizado dentro da empresa, o que permite que a empresa execute adaptações menores, mas suficientes para que o PNE exercite sua função.

A principal vantagem para o portador de necessidades especiais é a flexibilidade de horários e do local de trabalho, visto que os PNES, na maioria das vezes, buscam adaptar as suas casas às suas necessidades. Caso o trabalhador se encontre em conexão direta por meio do computador com o centro de dados da empresa, o empregador pode fornecer instruções e controlar a execução de trabalho, comprovando a qualidade e a quantidade de tarefas executadas pelo empregado.

Destaca-se que a remoção do empregado do interior da empresa para seu domicílio é possível mediante acordo entre as partes e desde que não acarrete prejuízo para o trabalhador, nos termos do art. 468 da CLT.

Segundo Suguimatsu, o teletrabalho não é um meio de eliminar o desemprego, não se confirmando acréscimo, nem decréscimo de postos de trabalho, e sim uma readequação profissional $^{41}$.

Por conseguinte, a utilização do teletrabalho como forma de inclusão no mercado de trabalho é uma alternativa rápida e viável, uma vez que traz inúmeras vantagens, tais como: maior autonomia na execução dos serviços; redução de gastos com locomoção, refeição e vestuário; diminuição do estresse provocado pelos problemas de trânsito; aumento de produtividade, em razão da proximidade e atenção familiar; aumento do tempo livre, permitindo maior acréscimo cultural ${ }^{42}$.

Outra forma de se auxiliar o PNE a fazer parte do mercado formal de trabalho é a criação de instituições que acompanhem os PNES e que os qualifiquem, encaminhando-os para os programas adequados aos seus tipos de necessidade. Existem diversas formas de necessidades especiais e o tratamento específico e adequado a cada uma delas, aliado ao encaminhamento profissional, propiciará ao PNE maiores condições de competitividade.

O incentivo fiscal para as empresas que empregarem PNES além da cota é uma ótima alternativa para que o mercado de trabalho seja receptivo aos portadores de

${ }^{41}$ SUGUIMATSU, Marlene T. Fuverki. O Teletrabalho - Diferenciadores Determinantes da Disciplina Jurídica Aplicável e a Proteção do Trabalhador. In: Roland Hasson (coordenador). Direito dos Trabalhadores \& Direitos Fundamentais. Curitiba: Juruá, 2003, p. 74.

${ }^{42}$ SUIGUIMATSU, op. cit., p. 80. 
necessidades especiais. Todavia, para que este incentivo alcance seu objetivo, é necessário que ele seja igual ou superior ao investimento que a empresa necessitará realizar para empregar o PNE.

Assim, conclui-se que a criação de novas frentes de trabalho que permitam aos PNES se integrarem ao mercado de trabalho é de suma importância. Entretanto, é necessário que as leis protetivas já existentes sejam cumpridas, afinal, todas possuem uma só finalidade, auxiliar o PNE a ter um tratamento social isonômico.

A melhor proposta em prol do PNE não é inovadora, e sim é aquela que visa protegêlo com os mecanismos já existentes (leis) e conscientizar a sociedade da necessidade contínua de aprimoramento (adaptação e habilitação).

\section{CONCLUSÃO}

Asseverou-se que as dificuldades de integração dos portadores de necessidades especiais na sociedade não é um problema recente, e sim, conseqüência de uma estigmatização provinda da antiguidade, a qual ainda é encontrada na atualidade.

A Constituição Federal de 1988 assegurou princípios como o da igualdade, da dignidade da pessoa humana e outros princípios sociais, abrangendo os PNES, especificamente, em alguns de seus artigos.

No entanto, importante salientar que a proteção legislativa ao PNE não ficou restrita às normas constitucionais, sendo de suma importância a complementação e regulamentação através da legislação infraconstitucional e o trabalho integrado da União, dos Estados e dos Municípios no exercício de suas competências, buscando a efetivação dessa legislação.

O mercado de trabalho é competitivo e segregativo, sendo mister o estímulo à criação e ao aperfeiçoamento de instituições que viabilizem de forma concreta a formação, a habilitação e a reabilitação profissional. Verificou-se, que apesar dessa constatação, são poucos os incentivos estatais e menor ainda o número de instituições que oferecem estes mecanismos de integração e inserção do PNE.

Ademais, outra grande dificuldade é a fiscalização, ou seja, os mecanismos que verificam a aplicação e a efetivação da legislação existente são ínfimos e esparsos, necessitando de implementação. 
A criação de programas e iniciativas que revelam a responsabilidade social é uma das formas de se conseguir com que as empresas assumam obrigações de caráter moral, além das obrigações já positivadas em lei, sendo necessário, por conseguinte, uma vigilância e exigência da sociedade, de modo a fazer com que as empresas assumam este compromisso.

Nesse passo, constatou-se que atualmente a sociedade, em sua maioria, exige que as empresas cumpram com sua função social, uma vez que a empresa é detentora de um grande poder sócio-econômico, sendo um importante agente de inclusão.

Destacou-se a relevância do Ministério Público como órgão responsável pela defesa dos interesses sociais, dando destaque ao Ministério público do Trabalho, o qual pode valerse de vários mecanismos, tal qual a ação civil pública.

Por conseguinte, para assegurar a efetivação da legislação existente, foram apresentados alguns dos mecanismos existentes no ataque à inércia na proteção do portador de necessidade especial, tais quais a ação civil pública, o mandado de segurança coletivo, o mandado de injunção e a ação direta de inconstitucionalidade por omissão. No entanto, averiguou-se a necessidade de veiculação da legislação protetiva para que a sociedade possa utilizar dos mecanismos citados para exigir sua concretização.

As políticas públicas também foram apresentadas como importantes mecanismos de implementação dos direitos sociais, sendo uma maneira de o Estado cumprir com a sua função e incentivar a sociedade a participar e a colaborar com a promoção dos direitos dos portadores de necessidades especiais.

No que concerne a habilitação e reabilitação profissional, concluiu-se serem um investimento a longo prazo, mas que podem trazer inúmeras vantagens, como a redução da discriminação e o aprimoramento do mercado de trabalho. Contudo, são atividades caras e complexas, de pouca incidência na sociedade brasileira, carecendo de incentivos do Estado e da conscientização social.

Ao final, foram apontadas algumas propostas que merecem credibilidade na proteção dos PNES. Dentre elas, destacou-se o teletrabalho, como forma de superação das barreiras arquitetônicas e flexibilização do mercado de trabalho. Mencionou-se, ainda, que a criação de instituições que acompanhem e qualifiquem os PNES para o mercado de trabalho é uma forma interessante de se integrar o PNE, a qual terá grande efetividade se aliada ao incentivo 
Estatal e se realizada parcerias entre estas instituições e as empresas, possibilitando a criação de novas frentes de trabalho.

Nesse diapasão, conclui-se pela necessidade de se respeitar e aplicar a legislação já existente, enfatizando a conscientização social e preparando os portadores de necessidades especiais para o mercado de trabalho, pois na maioria das vezes eles possuem limitações, o que não os impede de exercer plenamente uma função no mercado de trabalho.

\section{REFERÊNCIAS}

ARAUJO, Luiz Alberto David. A Proteção Constitucional das Pessoas Portadoras de Deficiência. $3^{\mathrm{a}}$ ed. Brasília: CORDE, 2003.

BARROS, Alice Monteiro de. Curso de Direito do Trabalho. 2 ed. São Paulo: LTr, 2006.

BASTOS, Celso Ribeiro. Curso de Direito Constitucional. 19ª ed. São Paulo: Saraiva, 1998.

BUENO, Carmem Leite. A Reabilitação Profissional e a Inserção da Pessoa com Deficiência no Mercado de Trabalho. Disponível em:

<http://www.prt12.mpt.gov.br/prt/guia/textos/reabilita.pdf>. Acesso em: 11 de jan. 2009.

COUTINHO, Adalcy Rachid. A autonomia privada: em busca da defesa dos direito fundamentais dos trabalhadores. In: Sarlet Ingo Wolfgang (organizador). Constituição, Direitos Fundamentais e Direito Privado. 2 ed. Porto Alegre: Livraria do Advogado, 2006.

DARCANCHY, Mara Vidigal. Teletrabalho e Acesso das Pessoas Portadoras de Necessidades Especiais ao Meio Ambiente do Trabalho. Revista Justiça do Trabalho, Porto Alegre: HS Editora, a. 23, n. 865, Janeiro/2006.

FERREIRA, Luiz Antonio Miguel. A Inclusão da Pessoa Portadora de Deficiência e o Ministério Público. Disponível em:

<http://www.institutointegrar.org.br/arquivos/A\%20INCLUSO\%20PESSOA\%20PORTAD ORA\%20DE\%20DEFICIENCIA.doc.>. Acesso em: 22 de jan. 2009.

GAGLIANO, Pablo Stolze. Novo Curso de Direito Civil. Volume IV: Contratos. 3 ed. São Paulo: Saraiva, 2007. 
KARKOTLI, Gilson. Responsabilidade Social Empresarial. Petrópolis, RJ: Vozes, 2006. MARQUES DA SILVA, Otto. A Epopéia Ignorada. São Paulo: CEDAS, 1986.

PASTORE, José. Oportunidades de Trabalho para Portadores de Deficiência. São Paulo: LTr, 2000.

PETTER, Lafayete Josué. Princípios Constitucionais da Ordem Econômica: O significado e o alcance do art. 170 da Constituição Federal. São Paulo: Revista dos Tribunais, 2005.

RIBAS, João Baptista Cintra. Emprego e Trabalho para Portadores de Deficiência. Disponível em: <http://www.lerparaver.com/node/272 >. Acesso em: 01 de maio 2009.

SILVA, José Afonso da. Curso de Direito Constitucional Positivo. 28 ed. São Paulo: Malheiros, 2007.

SUGUIMATSU, Marlene T. Fuverki. O Teletrabalho - Diferenciadores Determinantes da Disciplina Jurídica Aplicável e a Proteção do Trabalhador. In: Roland Hasson (coordenador). Direito dos Trabalhadores \& Direitos Fundamentais. Curitiba: Juruá, 2003. 